\title{
Using Complexity Science towards a Model for Disorders of Mind \& Body West Meets East Old Versus Modern
}

\author{
Wendy Thomson* \\ University of Portsmouth, UK
}

Received: May 16, 2018; Published: May 25, 2018

*Corresponding author: Wendy Thomson, University of Portsmouth, UK, Tel: 1983752928; Email: wendythomson7@icloud.com

\author{
Abstract \\ In their quest to understand consciousness \\ a) Disorder \\ b) Trying to place disordered health in the context of CAS \\ c) Lead me to study the equivalent in thermo dynamics phase transitions and hinge points which change from equilibrium to \\ disorder Complexity \\ d) Self-destruction a CAS?; a transparent and parallel system at all levels from top down and bottom upwards \\ e) We know there is matter and anti-matter \\ f) In Jungian terms we recognise a parall between the conscious and the unconscious the shadow? \\ g) Where is the a phase transition between the psyche ant the soma akin to phase transitions in physics with hinge points in \\ biology \\ h) Does the SDQ predict a phase transition between disorders in terms of health? \\ i) I am here to question and learn
}

\section{Introduction}

"All is One, and one is all". This tradition goes back as far as the sixth century BC in China where there is evidence that alchemy was practiced. Alchemists studied science holistically they were concerned with mind body and spirit the esoteric, and the exoteric which dealt with practical science. In 1890 William James in his Principles of Psychology wrote "As we take a general view of the wonderful stream of our consciousness, what strikes us first is the different pace of its parts. Like a bird's life it seems to first be made of an alternation of flights and perching's." Complexity and alchemy follow a tradition in the history and development of science. They operate a top down as opposed to bottom up approach. The new physics of the twentieth century reaffirms the ancient alchemical insights depicting the universe as a field of forces and a constant flow of transforming energy. An example is the Gaia concept of James Lovelocks who promotes Gaia as a living organism. and ecology, which presents nature as a complex web of relationships. Heisenberg's reality principle can be seen if you like as the bridge which unites the esoteric with exoteric. The epic study of Hinkle \& Wolffe [1957] dealing with psychosomatic investigation found disorder - illnesses both physical and mental, and accidents clustered and appeared to be cyclical.

However, returning to the quest of the alchemists to transform humans from base matter to refined spirit and to produce nothing less than the gold of spiritual illumination is not the aim today. The aim today is to consider a alternative model on which to base disorder. The medical model of disease causation was formulated in a response to the mechanistic approach and some feel this is responsible for a gulf between the mind and the body in medicine favoring the body. Plato gives the reason why the cure of many diseases was unknown to the physicians of Hellas and he blamed the disregard of the whole.

In the Twentieth Century, the Science of Complexity and the Physics of Complex Systems Span the Principles of: 
a. Quantum and statistical mechanics,

b. Information theory,

c. Nonlinear dynamics and chaos, and discrete systems.

These fields have provided techniques and approaches to understanding and to problem solving that are useful across the sciences, and serve as points of departure for the recognition of new principles.

\section{My background}

I first became interested in complexity in the early 1990's although at that time no-one knew anything about it. I actually bought a book in Water stones in Bristol. I wanted to go to Santa Fe the centre of complex adaptive systems, but at that time it was out of the question. So I had to content myself with reading books and articles. The idea of everything being connected appealed to me. I had grown up on a farm, a close knit community where everything and everybody was interdependent, weather, crops, cattle, harvest, and the markets outside the farm. Farmers are very intuitive and often spiritual so even the esoteric was represented. My family even thought that you should stay on the soil where you had your roots and eat and drink from the food and water it produced. I provoked them by going to Canada.

Although in the early nineties I could not belong to a group or study complexity what I read seriously influenced my thinking. David Bohm, Jung, Lovelock. I even rang Brian Godwin suggesting we needed a base in the UK and I suggested Darlington in Devon. I had gathered experience in the different cultures of Canada and Africa. Working amongst the sick first the physically ill, and then the mentally ill I saw the crises my patients were experiencing sometimes as predictable. I could not fail to notice the individual differences in my patients. Some would be able to adapt to inevitable events in their lives while other would not. I saw the web of the negativity in their lives reinforcing and fueling further negativity. My own research reflected this. Instead of viewing the content I began viewing the form. Substituting the diagnosis as the form for a hypothesized self-defeating system congruent with complexity theory. [The diagnosis became the content].

After my introduction to research I realized I could formulate hypotheses and test them. Eventually after completing various research projects I began with the help of my limited knowledge of complexity to see how limited some theories and practices were in the field of psychiatry. So much information was omitted thus contributing to error. I conceived the mental illness of my patients as a tangle of self - sabotaging self - defeating ideation. I further hypothesized that self - defeating ideation begins in the human psyche and has the propensity to radiate outwards to include the ecology, the biosphere and the physiosphere. This ideation is at odds with the idea that society generates stress and that the individual is a victim. It promotes the notion that we create the stress Evans [1981] \& Evans [1985] to which we then react which was the result of some of my research. Carried to its conclusion this idea is consistent with the view that ultimately we have the capacity to destroy our earthly home, and that we can annihilate ourselves as believed by the sci- entists moving the hands of the atomic clock.

Complexity theorists explain how this process can begin and end extremely quickly and therefore gives little time to adapt. Per a physicist at Brook haven National Laboratory New York explains CAS maybe biological like a coevolving ecosystem, or a physical system but once they reach a critical state they display one very characteristic property - perturb such a system and there may be a small response. Perturb it again with the same degree of disturbance and it might collapse completely explained by a power law distribution. They are also difficult to predict a collapse unless they are identified as CAS. Theorists cite examples of civilizations thought to be everlasting and impregnable - tumble. Examples recently of Glasnost and the fall of the Soviet Union before that Whatever the level micro to macro the same dynamics can be applied. Mankind can be viewed as a system - a complex adaptive system made up of each individual with the same characteristics; the ability to sustain order or react to disorder and either adjust or cease. Individuals can ride the turbulence and progress regroup or collapse. Examples are Selye's General adaptation syndrome or suicide following a depressive illness. Another characteristic of a CAS is they begin as very simple and develop into the complex.

\section{My Own Research}

My own journey has been concerned with those who have not been able to take steps towards attaining the gold of spiritual illumination - patients. They have neither been able to achieve this alone or with the help available by the National health Service. When they attend for treatment they are placing themselves in the hands of psychiatrists and the like hoping that the pessimism associated with the diagnosis depression from which they suffer can be understood and treated. However, the outcome for people with this diagnosis is very unsatisfactory and in my research Thomson [1996], I found that some patients take the decision consciously to end their lives by committing suicide, which is known, [15\%]. However, what is largely unknown is that a number will die prematurely from natural causes raising the possibility that we can invoke an unconscious mechanism, which will cause premature death.

\section{The Nature of Complexity}

The understanding of complex systems refutes the reductionist bottom-up approach of traditional science. The latter assumes that the underlying mechanisms of a system's behaviour can be understood by studying the system parts independently. A complex system, however, is more than the sum of its parts. Its behaviour comes about through "interaction between the constituent parts". Although the term "complex system" has multiple usages, some of the properties of a complex system, generally agreed upon are:

a. It consists of many parts, out of whose interaction "emerges" behaviour not present in the parts alone.

b. It is amalgamated to an environment with which it exchanges energy, information, or other types of resources.

c. It exhibits both order and randomness -- in its (spatial) structure or (temporal) behaviour. 
d. There is no central control element, neither internal nor external.

e. The structure / behaviour is robust against significant perturbation.

\section{f. The system has memory and feedback.}

g. The system can adapt itself according to its history or feedback

Examples of complex systems can be found in all areas of science -- non-linear dynamical systems (mathematics), networks (statistics), non-equilibrium chemical reactions (chemistry), protein interaction networks (molecular biology), the brain (neuroscience), ant colonies (animal behaviour), cellular automata (computer science), market behaviour (economics), to mention a few examples. Counter to what the above list suggests, the study of these systems requires combining methods from more than one discipline as well as the development of new mathematical and computational tools. Examples West, former Postdoctoral Fellow Van Savage and former Physicist Alex Herman are exploring the role of scaling in the study of tumor growth and vascularization. For tumors the theory must successfully describe the interface and integration of two coupled, but essentially autonomous, dynamical networks: the host and the tumor. Thus, in addition to addressing an important biomedical question, this potentially provides a sensitive test of the theory.

West and SFI External Professor Walter Fontana, and collaborators at Temple and Louisville medical schools have formed a largescale collaboration on aging, mortality and lifespan to address why humans live for $\sim 100$ years rather than a few months or thousands of years, and why mice live for only 2-3 years, even though they are made of essentially the same tissue? Where in the molecular structure of genes and respiratory enzymes, which operate at microscopic time scales, are time scales of years? Hints can be gleaned from scaling. Lifespan, like almost all life-history events, scales as $\sim \mathrm{M} 1 / 4(53,270)$. Additionally, both total lifetime energy needed to sustain unit mass and the number of turnovers of CytO molecules in mitochondria per lifetime are invariants (318). This suggests that a generic fundamental dynamical theory of longevity and senescence can be constructed. West, Fontana and collaborators are addressing this possibility by questioning if the origin of aging is dissipative forces (e.g. free radical damage via metabolism) and subsequent entropy production in supply networks, which ultimately produce irreversible damage at the molecular level.

The central and peripheral nervous systems are also hierarchical branching networks which exhibit scaling: the vertebrate brain scales non-linearly with body size, $\sim \mathrm{M} 3 / 4(53,270)$, and the grey to white matter ratio ("cables to processors") M5/4 (341). Brain architecture has the remarkable property that computational power is increased simply by increasing the number of neurons. SFI Professor Geoffrey West and SFI External Professor Chuck Stevens are investigating how these can reveal new laws that neuronal components follow and decide what sorts of mathematical operations neuronal circuits carry out. This will involve both theoretical and experimental work (primarily on fish at the Salk Institute).
In my own research concerning personality, stress, and mental illness, I have been fascinated by the mediating mechanisms, which interact and play a part in determining outcomes, between health and disorder. The analysis and the testing for significance by designing a study comparing variables such as stress and personality, or mortality and depression. This has shades of the amateur about it and left out more that it included, it was piecemeal. Take for example one study which I completed The Mortality of Depression Thomson [1996]. I designed a prospective 24 year follow-up study of 685 depressed patients and compared the mortality rate with a normal control. I found a doubling of the death rate. Not just from unnatural death due to suicide etc, but from natural death as well, which included respiratory illness, heart disease, cancer, and other physical illnesses. What made this finding so interesting to me was that death from natural disease is not part of the natural history of depression. Which I now refute.

Nevertheless, for me the most alarming discovery was the time of death. Highly significant death occurred in the early years after discharge when the patients should have been better why? Numerous hypotheses were considered. The answer remains speculative. Another revelation was that, although theory dictates practice, in depression there are 44 theories of depression. So with these severe flaws in the theory of a depressive illness how successful can the treatment of depression be? It questions the weakness within the professions treating depressed patients and that no one theory can be agreed upon. In 1999 I attended a World Health Organization meeting in collaboration with the International Federation of Health Funds \& Harvard School of Medicine, on depression titled - Social \& Economic Time Bomb. The meeting was chaired by Professor Arthur Kleinman Professor of psychiatry, and Professor of social anthropology at Harvard. His opening remark was 'Depression raises enormously important questions 'It is imperative that in twenty years depression will account for a greater proportion of human morbidity than any other disease other than ischemic heart disease". The conclusion from all this; the stigma the misery, the social and economic consequences the failure of treatment and resulting premature mortality, the rising prevalence suggests that what we do about it must be effective and based on an viable theory.

I recognized that my research is limited, by trying to isolate the component elements of mental illness in this case depression and examining the relationship which exist between them. It occurred to me that this is a very clumsy method of trying to understand the complexity of mental illness, and that depression might best be studied by studying the whole patient and not the component parts. To this end, while I was at Bristol I designed the SDQ Self-defeating ideation Quotient. The purpose was to go beyond the Maudsly Assessment schedule and to obtain information from the patients themselves at referral. Using the concept from complexity, I hypothesized that depression becomes the content of a Self-defeating ideation System and the SDS becomes the form. In other words, I was seeing the other side or the shadow side in Jungian terms of humankind. It made sense to me that although complexity studies systems it takes two systems to make the whole and part of the whole is the negative. 
Why is it so important to establish theory of depression and of any mental illness? Quite apart from reducing the misery and premature mortality improving the effectiveness and efficiency off intervention must be paramount.

Present funding for the mentally ill is woefully inadequate competing with resources for neonatal care, surgery, and cancer, the recognized life threatening disorders. The move from cure to care downgrades treatment provision for all disorders but most particularly mental illness, resulting in systemic inadequacies resulting;

a. Insufficient time available for initial assessment.

b. Insufficient contribution from the patients themselves.

c. Blanket approaches to treatment.

d. Lack of and diffusion of accountability from service providers diminution of the responsibility of the doctor in charge.

The serious stigma associated with mental illness does nothing but demean the status of the mentally ill, and can only further hamper recovery. The different frame of reference from that of a patient with a physical illness is evident. It is not unusual for patients to ask: can I, am I, shall I go mad? To test my hypotheses, which was that depression is part of a Self - destructive trait; systematic in character I did the following; I designed a questionnaire, which I called the Self Defeating Quotient.

\section{Methods}

\section{Self-Defeating Questionnaire}

The Self Defeating Questionnaire (SDQ) was developed by the author for the purposes of the present investigation. Items for the SDQ were piloted with patients who were undergoing treatment for depression, and were revised in consultation with treating psychiatrists. The SDQ consists of 33 statements describing elements of the respondents' behaviour and feelings, and is administered in two parallel forms: one describing the extent to which the statement describes the actual behaviour or feelings of the respondent (the Now form), and the other indicating the ideal level of each item (the Ideal form). The response scale used was a $10 \mathrm{~mm}$ line, which represented a continuum of response. Illustratively, the Control item asks participants to indicate how much control they have over "things that made them feel optimistic and content." Participants

Table 1: Descriptive Statistics for EPQ Now and Ideal Items. responded to this item by indicating whether they had Total Control or No Control (Appendix A shows the full set of SDQ Now and Ideal items).

Subjects were asked to mark their response to each item on the line. Responses were coded from 0 to 100. At the one extreme, the preferential state or behaviour was represented by a score of 0 , while a negative response was indicated by a score of 100 . The SDQ Now Total is scored by computing the average SDQ Now rating items. The SDQ Ideal Total score is computed as the average Ideal rating of the items. The SDQ Total Discrepancy score is computed by subtracting the Ideal score from the Now score. Higher discrepancy scores indicate a greater difference between ideal and perceived behaviours and feelings, and are interpreted as an indicator of increased risk for self-harm. The factor structure of the SDQ will be examined in the present investigation.

\section{Sample}

The present study utilized data from 95 participants. A substantial portion of the sample received psychiatric care for depression: $57.4 \%$ of the sample received treatment for depression, while the remaining $42.6 \%$ of the sample served as normal controls. Females comprised $57 \%$ of the sample, while $43 \%$ were male. The median age of the study participants was 55 years old. With respect to employment status, $40 \%$ of the sample was employed full-time, $25.3 \%$ were employed part-time, and $1.1 \%$ was self-employed. A further $16.9 \%$ were unemployed, $8.4 \%$ were disabled, $4.4 \%$ were retired, and $4.2 \%$ were homemakers. Pre-existing medical conditions were present in $47.8 \%$ of the sample.

\section{Results Self-Destruction Questionnaire}

All 95 subjects who participated in this investigation provided valid data on the SDQ. Mean scores for the SDQ items in Now and Ideal forms are shown in Table 1. With few exceptions, ratings of items on the Now form are higher than ratings on the Ideal form, indicating that, on average, subjects say their actual behaviours and feelings as less than ideal. Two exceptions to this general trend concern the Weight and Drugs items. For the Weight item, neither the Now nor the Ideal ratings were very positive. For the Drugs items, both the Now and the Ideal ratings were extremely positive, indicating that participants did not use non-prescription drugs or value drug use.

\begin{tabular}{|c|c|c|c|c|}
\hline & & Now & Ideal & Mean \\
\hline SDQ Item & Mean & S.D & 14.3 & 16.9 \\
\hline Diet & 38.1 & 24.4 & 45.8 & 17 \\
\hline Weight & 37.4 & 17.9 & 27.2 & 20.3 \\
\hline Alcohol & 33.3 & 25.6 & 19.4 & 19.3 \\
\hline Exercise & 48.8 & 28 & 5.6 & 14.8 \\
\hline Drugs & 4.5 & 13 & 7.1 & 15.2 \\
\hline Smoking & 23 & 21.9 & 10.4 & 12.3 \\
\hline Care & 33.7 & 21.9 & 17.6 & 22.1 \\
\hline Stress & 60.1 & 27.4 & 6.9 & 10.3 \\
\hline Contentment & 47.7 & 28.5 & & \\
\hline
\end{tabular}




\begin{tabular}{|c|c|c|c|c|}
\hline Jealousy & 35.6 & 29.1 & 9 & 15.9 \\
\hline Temper & 39.6 & 28 & 13.3 & 18.6 \\
\hline Debt & 23.7 & 27.6 & 4.8 & 9.1 \\
\hline Control & 43.1 & 28.8 & 8.8 & 13 \\
\hline Family & 12.8 & 18.3 & 8.1 & 13.8 \\
\hline Initiative & 31 & 26.6 & 7.5 & 11.9 \\
\hline Aggression & 27 & 28.7 & 6.1 & 13.6 \\
\hline Family Time & 37.3 & 30.7 & 8.8 & 16.9 \\
\hline Neighbours & 27.4 & 27.3 & 8.7 & 15.1 \\
\hline Work & 33.9 & 26.1 & 6.4 & 10.8 \\
\hline Colleagues & 24.8 & 18.2 & 9.2 & 12.9 \\
\hline Country & 40.7 & 25.6 & 19.3 & 19.7 \\
\hline Community & 56.3 & 28.7 & 24 & 26.3 \\
\hline Law & 21.6 & 27.3 & 12.6 & 21.4 \\
\hline Conservation & 25.2 & 24.9 & 12.3 & 20.5 \\
\hline Vandalism & 12.6 & 16.2 & 9 & 16.5 \\
\hline Honesty & 11.7 & 17.5 & 6.1 & 13.6 \\
\hline Elections & 24.8 & 31.7 & 18.9 & 26 \\
\hline Altruism & 27 & 22.9 & 14 & 18 \\
\hline Early Education & 37.7 & 28.3 & 13.3 & 18.8 \\
\hline Adult Training & 38.4 & 30.7 & 14.5 & 22.4 \\
\hline Childhood & 45.2 & 32 & 13.5 & 21.5 \\
\hline Problems & 56.4 & 27.4 & 15.9 & 19.5 \\
\hline Destruction & 21.2 & & 9.4 & 15.7 \\
\hline
\end{tabular}

\section{Structure of The SDQ}

Factor Analysis of the SDQ: To investigate the underlying dimensional structure of the SDQ, factor analyses were conducted. The scree plot of the eigenvalues (Cattell, 1966) suggested that four factors should be retained for analysis. Both varimax and oblique rotations of the factors were conducted (Harman, 1976). The results of both rotations were consistent and interpretable. Findings from the varimax rotation are presented below. The results of the factor analysis for the SDQ Now are shown in Table 2. Loadings below 3 have been omitted for the sake of clarity. In the analysis of the SDQ Now form, the first factor has high loadings on a broad range of issues pertaining to emotional well being, personal habits, and community affairs. The second factor has high loadings for items related to social contexts that foster human development. The third factor loads on items pertaining to social control. The fourth factor has high loadings for items dealing with the protection of property and the environment.

Table 2: SDQ Factor Structure (Now Form).

\begin{tabular}{|c|c|c|c|c|}
\hline Item & Factor 1 & Factor 2 & Factor 3 & Factor 4 \\
\hline Control & .646 & & & \\
\hline Contentment & .584 & & & \\
\hline Stress & .579 & & & \\
\hline Problems & .579 & & & \\
\hline Jealousy & .522 & .345 & & \\
\hline
\end{tabular}

\begin{tabular}{|c|l|l|l|l|}
\hline Elections & .460 & & & \\
\hline Initiative & .445 & .306 & & \\
\hline Debt & .433 & & & \\
\hline Exercise & .419 & & & \\
\hline Diet & .409 & & & \\
\hline Neighbour & .405 & & & \\
\hline Country & .377 & & & \\
\hline Community & .365 & & & \\
\hline & & .748 & & \\
\hline Education & & .734 & & \\
\hline Adult Training & & .592 & & \\
\hline Colleagues & & .531 & & \\
\hline Childhood & & .515 & & \\
\hline Work & & .466 & & \\
\hline Family Time & & .415 & & \\
\hline Altruism & & & & \\
\hline Honesty & & & .519 & \\
\hline Care & .393 & .384 & .492 & \\
\hline Law & & & .488 & \\
\hline Temper & .435 & & .475 & \\
\hline Aggression & .356 & & .475 & \\
\hline Drugs & & & .408 & \\
\hline Alcohol & & & .400 & \\
\hline
\end{tabular}




\begin{tabular}{|c|l|l|l|l|}
\hline Smoking & & & .359 & \\
\hline Conservation & & & & .790 \\
\hline Destruction & & & & .425 \\
\hline Vandalism & & & & .378 \\
\hline Weight & & & & \\
\hline
\end{tabular}

Scoring of the SDQ Scales: The results of the four-factor solution for the SDQ-Now scales were utilized to develop the scoring framework for the SDQ scales. Because the first factor encompassed items related to a broad range of topics, this dimension was further divided into three scales on conceptual grounds. Specifically, the Emotional Well-Being scale was computed as the average rating of items dealing with Control, Initiative, Contentment, Stress, Problems, and Jealousy. The Community Affairs scale was computed as the average rating for items dealing with Elections, Neighbours, Country, and Community. The Personal Habits scale was computed as the average of items related to Diet and Debt. The items with high loadings on the second factor comprised the Developmental Contexts scale. Specifically, this scale was computed as the average

Table 3: Correlation of SDQ Now and EPQ Scales. rating of items pertaining to Early Education, Adult Learning, Colleagues, Childhood, Work, Family, Family Time, and Altruism. Results from the third factor shaped the scoring of the Social Control scale, which was computed as the average of items related to Honesty, Caring, Law, Temper, Aggression, Drugs, Alcohol, and Smoking. Lastly, the items loading on the fourth dimension formed the Protection and Conservation scale.

SDQ Now and Personality: In order to examine the association between SDQ Now dimensions and personality, correlation analyses were conducted see Table 3. Scores on the EPQ Neuroticism scale were significantly related to a wide range of SDQ Now scales. Subjects with higher levels of Neuroticism had higher scores (i.e., more negative appraisals) of their Emotional Well-Being, Community Affairs, Personal Habits, Developmental Contexts, and Social Control. These subjects also had lower scores (i.e., more positive appraisals) on the Conservation scale. In addition, subjects with higher Extraversion scores had significantly lower scores on ratings of Developmental Contexts, while those with higher scores on Dissimulation had lower scores on Social Control.

\begin{tabular}{|c|c|c|c|c|}
\hline SDQ Now Scale & Psychoticism & Extraversion & Neuroticism & Dissimulation \\
\hline Emotional Well-Being & .114 & -.157 & $.552^{* * *}$ & .017 \\
\hline Community Affairs & .116 & -.143 & .188 & -.239 \\
\hline Personal Habits & .222 & .155 & $.334^{* *}$ & -.239 \\
\hline Developmental Contexts & .038 & $-.385^{* *}$ & $.320^{*}$ & -.215 \\
\hline Social Control & .135 & .114 & $.261^{*}$ & $-.490^{* * *}$ \\
\hline Conservation/Preservation & -.073 & .000 & $-.278^{*}$ & -.021 \\
\hline
\end{tabular}

Note: ${ }^{*} \mathrm{P}<.05 ;{ }^{* *} \mathrm{p}<.01 ;{ }^{* *} \mathrm{p}<.001$

SDQ Ideal and Personality: Correlational analyses were conducted to examine the association between the SDQ Ideal scales and the EPQ see Table 4. The EPQ Neuroticism scale was significantly related with numerous SDQ Ideal scales. Subjects with higher Neuroticism scores had lower SDQ Ideal scores on Personal
Habits, Developmental Contexts, and Conservation (indicating that more neurotic subjects had higher standards in these areas). The correlations of Neuroticism with SDQ Ideal scores for Emotional Well-Being and Social Control barely failed to attain statistical significance at alpha $<.05$.

Table 4: Correlation of SDQ Ideal and EPQ Scales.

\begin{tabular}{|c|c|c|c|c|}
\hline SDQ Now Scale & Psychoticism & Extraversion & Neuroticism & Dissimulation \\
\hline Emotional Well-Being & -.031 & .120 & -.235 & -.086 \\
\hline Community Affairs & -.041 & .011 & -.086 & .021 \\
\hline Personal Habits & -.072 & .178 & $-.279^{*}$ & -.092 \\
\hline Developmental Contexts & .013 & -.010 & $-.273^{*}$ & -.205 \\
\hline Social Control & .090 & .075 & -.249 & -.221 \\
\hline Conservation/Preservation & .021 & .166 & $-.426^{* * *}$ & -.045 \\
\hline
\end{tabular}

Note: ${ }^{*} \mathrm{P}<.05 ;{ }^{* *} \mathrm{p}<.01 ;{ }^{* *} \mathrm{p}<.001$

Discrepancy on SDQ Subscales and Personality: In order to examine the relationship between Now-Ideal discrepancy scores on the SDQ and personality, co relational analyses were conducted see Table 5. The personality dimension of Neuroticism was associated significantly with discrepancy scores in multiple domains of the SDQ. Subjects with higher Neuroticism scores had significantly higher discrepancy scores for Emotional Well-Being, Community Affairs, Personal Habits, Developmental Contexts, and Social Con- trol. The magnitude of the relationships between Neuroticism and the discrepancy scores is noteworthy. Neuroticism accounted for more than 20 percent of the variance in discrepancy scores related to Personal Habits, Developmental Contexts, and Social Control, and more than 36 percent of the variance in discrepancy scores related to Emotional Well-Being. Few significant relationships were found for other EPQ personality dimensions. Subjects with higher Psychoticism scores had higher discrepancy scores for Personal 
Habits. Subjects with higher Extraversion scores had lower discrepancy scores for Developmental Contexts, while those with higher Table 5: Correlation of SDQ Discrepancy and EPQ Scales.
Dissimulation; scores had significantly lower discrepancy scores for Social Control.

\begin{tabular}{|c|c|c|c|c|}
\hline SDQ Now Scale & Psychoticism & Extraversion & Neuroticism & Dissimulation \\
\hline Emotional Well-Being & .118 & -.207 & $.622^{* * *}$ & .064 \\
\hline Community Affairs & .155 & -.159 & $.265^{*}$ & -.265 \\
\hline Personal Habits & $.255^{*}$ & .029 & $.495^{* * *}$ & -.165 \\
\hline Developmental Contexts & .027 & $-.353^{* *}$ & $.471^{* * *}$ & .070 \\
\hline Social Control & .074 & .063 & $.453^{* * *}$ & $-.341^{* *}$ \\
\hline Conservation/Preservation & -.092 & -.141 & .083 & .017 \\
\hline
\end{tabular}

Note: ${ }^{*} \mathrm{P}<.05 ;{ }^{* *} \mathrm{p}<.01 ;{ }^{* *} \mathrm{p}<.001$

SDQ Scores and Psychiatric Status: Having found significant relationships between Neuroticism and the SDQ dimensions, the next stage of the analyses examined the question of how well the SDQ differentiated clinically depressed and normal control subjects.

SDQ Now Scores for Depressed and Control Subjects: Scores on the SDQ-Now for clinically depressed and control subjects are shown in Table 6. T-tests were conducted to test the statistical significance of differences between groups. Clinically depressed subjects had significantly higher mean scores (i.e., more negative appraisals) on the Emotional Well-Being scales of the SDQ.

Table 6: SDQ Now Scores Among Clinically Depressed and Control Subjects.

\begin{tabular}{|c|c|c|c|}
\hline SDQ Now Scale & Mean & Mean & t-value \\
\hline Emotional Well-Being & 52.0 & 36.6 & $3.98^{* * *}$ \\
\hline Community Affairs & 38.9 & 34.6 & 1.088 \\
\hline Personal Habits & 36.3 & 36.8 & 0.125 \\
\hline Developmental Contexts & 34.0 & 29.3 & 1.323 \\
\hline Social Control & 25.0 & 22.8 & 0.781 \\
\hline Conservation/Preservation & 19.6 & 19.9 & 0.084 \\
\hline
\end{tabular}

Note: ${ }^{*} \mathrm{P}<.05 ;{ }^{* *} \mathrm{p}<.01 ;{ }^{* *} \mathrm{p}<.001$

SDQ Ideal Scores for Depressed and Controls Subjects: SDQ-Ideal scores for clinically depressed and control subjects are shown in Table 7. No statistically significant differences were found between groups on the SDQ-Ideal scales.

Table 7: SDQ Ideal Scores Among Clinically Depressed and Control Subjects.

\begin{tabular}{|c|c|c|c|}
\hline SDQ Now Scale & Mean & Mean & t-value \\
\hline Emotional Well-Being & 11.1 & 10.7 & 0.191 \\
\hline Community Affairs & 20.7 & 14.1 & 1.834 \\
\hline Personal Habits & 11.7 & 13.6 & 0.812 \\
\hline Developmental Contexts & 11.3 & 10.9 & 0.154 \\
\hline Social Control & 10.8 & 11.2 & 0.478 \\
\hline Conservation/Preservation & 11.1 & 9.3 & 0.588 \\
\hline
\end{tabular}

SDQ Discrepancy Scores for Depressed and Control Subjects: SDQ Discrepancy scores for clinically depressed and control subjects are shown in Table 8. Significant group differences were found for the Emotional Well-Being dimension. Depressed subjects had significantly higher Now-Ideal discrepancy scores compared with normal controls.

Table 8: SDQ Discrepancy Scores among Clinically Depressed and Control Subjects.

\begin{tabular}{|c|c|c|c|}
\hline SDQ Now Scale & Mean & Mean & t-value \\
\hline Emotional Well-Being & 40.9 & 25.9 & $3.494^{* * *}$ \\
\hline Community Affairs & 18.1 & 20.6 & 0.725 \\
\hline Personal Habits & 24.6 & 23.3 & 0.318 \\
\hline Developmental Contexts & 22.6 & 18.5 & 1.138 \\
\hline Social Control & 14.3 & 11.1 & 1.096 \\
\hline Conservation/Preservation & 8.2 & 10.6 & 0.763 \\
\hline
\end{tabular}

Note: ${ }^{*} \mathrm{P}<.05 ;{ }^{* *} \mathrm{p}<.01 ;{ }^{* *} \mathrm{p}<.001$

It was considered imperative that greater understanding of the mechanism involved should be investigated further, the more so because, of the burden of depression, the prevalence, the suffering, and the social and economic consequences are so concerning [Kouzis A Eaton WW, Leaf PJ. [1995] An attempt had been made to explain the results found in Evans [1996] retrospectively. One such speculation was that the actual psychological state associated with depression could cause premature mortality TABLE 9. This was likened to the Voodoo death described by Canon [1942] and Milton [1973]. In other words, it posed the question is it possible to die of natural causes via a self-destructive mechanism other than by unnatural death. If this were to be accepted then there are a number of associated factors, which would demand consideration amongst them being the implications for funding alongside life threatening diseases such as cancer and heart disease.

Table 9: SDQ Discrepancy Scores among Clinically Depressed and Control Subjects

\begin{tabular}{|c|c|c|c|}
\hline & Depressed & Control & \\
\hline SDQ Now Scale & Mean & Mean & t-value \\
\hline Emotional Well-Being & 40.9 & 25.9 & $3.494^{* *}$ \\
\hline Community Affairs & 18.1 & 20.6 & 0.725 \\
\hline Personal Habits & 24.6 & 23.3 & 0.318 \\
\hline Developmental Contexts & 22.6 & 18.5 & 1.138 \\
\hline Social Control & 14.3 & 11.1 & 1.096 \\
\hline
\end{tabular}




\begin{tabular}{|c|c|c|c|}
\hline Conservation/Preservation & 8.2 & 10.6 & 0.763 \\
\hline \multicolumn{4}{|c|}{ Note. } \\
\hline \multicolumn{3}{|c|}{${ }^{*} \mathrm{p}<.05 ;{ }^{*} \mathrm{p}<.01 ;{ }^{* *} \mathrm{p}<.001$} \\
\hline
\end{tabular}

\section{What did I find?}

a) That self - destruction is a trait.

b) The SD Trait is present in both the normal and the mentally ill cohort.

c) Medical conditions were found significantly more often among clinically depressed subjects.

d) Loss of control is a feature

e) Personality is a feature

f) That factoring demonstrates just how pervasive the SD is Table

\section{Discussion}

It was considered imperative that greater understanding of the mechanism involved should be investigated further, the more so because, of the burden of depression, the prevalence, the suffering, and the social and economic consequences are so concerning Kouzis A Eaton WW, Leaf PJ. An attempt had been made to explain the results of the mortality study Evans 1996, retrospectively but they were considered inadequate. Indeed, this association was quite strong: physical illness was twice as common among clinically depressed patients as it was among normal controls. The depressed patients exhibited more SD ideation than the normal controls.

One such speculation was that the actual psychological state associated with depression could cause premature mortality. This is likened to the Voodoo death described by Canon 1942 and Milton 1973. In other words, it posed the question is it possible to die of natural causes via a self-destructive mechanism other than by unnatural death. If this were to be accepted then there are a number of associated factors, which would demand consideration amongst them being the implications for funding alongside life threatening diseases such as cancer and heart disease. Can this work be continued using complexity theory and analysis? Does it fit the criteria of a complex adaptive system I believe it does.
This work is licensed under Creative Commons Attribution 4.0 License

Submission Link: https://biomedres.us/submit-manuscript.php

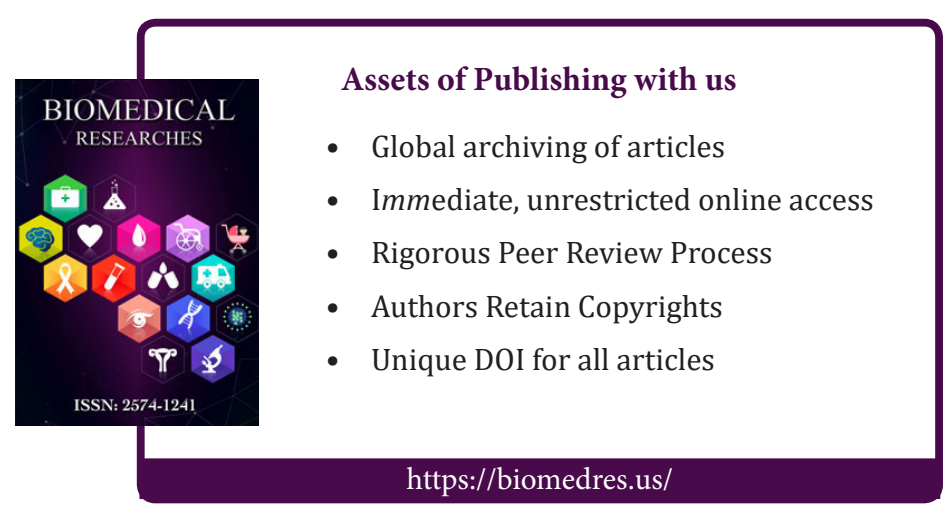

